\title{
CLASSIFICAÇÃO DE AMOSTRAS DE CAFÉ USANDO VISÃO COMPUTACIONAL
}

\author{
VASCONCELLOS, B. M.*. ALMEIDA, G. M.** \\ CONTARATO, R. B.***. ALMEIDA, R.**** \\ *Instituto Federal do Espírito Santo - Campus Serra, ES, Brasil, 29173-087 \\ (e-mail: brunomeschiatti@gmail.com). \\ **Instituto Federal do Espírito Santo - Campus Serra, ES, Brasil, 29173-087 (e-mail:gmaia@ifes.edu.br) \\ ***Instituto Federal do Espirito Santo - Campus Serra, ES, Brasil, 29173-087(e-mail:rodrigo.contarato@hotmail.com) \\ ****Instituto Federal do Espirito Santo - Campus Serra, ES, Brasil, 29173-087 (email: ricalme@hotmail.com)\}
}

\begin{abstract}
The world's coffee agribusiness is worth US \$ 91 billion annually and involves a half billion people. It is in this gigantic market that the interest of the Brazilian coffee production chain is placed, which contributed with more than $30 \%$ of the world production in the last harvests. The coffee market is characterized by a combination of activities of enormous complexity, dynamism, and a growing level of consumer demand for beverage quality. This imposes a high-quality control on producing, consuming and exporting countries. Currently, the definition of quality and hence the value of coffee is based on manual grading, so, a person performs the role of a trained (certified) classifier to qualify coffee samples. Thus, the current coffee grading process suffers from the subjectivity of the classifiers and a great difficulty to pave the process due to possible inconsistencies. The present work proposes the use of Fuzzy Logic for the analysis of coffee bean samples by digital image analysis, in order to increase the speed and reduce the subjectivities involved in the current manual classification process, shape, size and colour. Among the benefits of the automation of the coffee classification process are the reduction of costs, the agility and the standardization of the classification.
\end{abstract}

Resumo: O agronegócio mundial do café engloba, anualmente, recursos que chegam a 91 bilhões de dólares e envolve meio bilhão de pessoas. É nesse mercado gigantesco que está centrado o interesse da cadeia produtiva do café brasileiro, que contribuiu com mais de $30 \%$ da produção mundial nas últimas safras. O mercado do café é caracterizado por um conjunto de atividades de enorme complexidade, dinamismo, e um crescente nível de exigência dos consumidores quanto à qualidade da bebida. Isso impõe aos países produtores, consumidores e exportadores um elevado controle de qualidade. Atualmente, a definição da qualidade e, portanto, do valor do café é baseada na classificação manual, ou seja, uma pessoa exerce o papel de um classificador treinado (certificado) para qualificar as amostras de café. Assim, o processo atual de classificação de café sofre com a subjetividade dos classificadores e uma grande dificuldade de padronização do processo devido a possíveis inconsistências. O presente trabalho propõe o uso de aprendizado não-supervisionado de máquina, através de clusterização (K-Means) para análise de amostras de café em grãos pela análise de imagens digitais, a fim de se aumentar a velocidade e reduzir as subjetividades envolvidas no atual processo manual de classificação, considerando: forma, tamanho e cor.. Dentre os benefícios da automação do processo de classificação de café destacam-se a redução de custos, a agilidade e a padronização da classificação.

Keywords: Machine Learning; Computational Vision; K-Means; White-Patch; Clustering.

Palavras-chaves: Aprendizagem de Máquinas; Visão Computacional; K-Means; White-Patch; Clusterização.

\section{INTRODUÇÃO}

Desde o século XIX o Brasil tem se destacado na produção e exportação de café, e atualmente ocupa a primeira posição mundial tanto na produção como na exportação do produto, contando com cerca de $30 \%$ do total das exportações mundiais do café (ICO, 2014).
Devido à alta exigência do mercado internacional por produtos de qualidade, o café brasileiro exportado necessita passar por um rígido controle de qualidade, o qual deve ser preciso e rápido, dado o grande volume do produto que deve ser avaliado. Esse controle diz respeito tanto ao café em pó quanto ao grão antes da torrefação e da moagem. 
Um dos desafios que as cooperativas de café enfrentam atualmente é avaliar a qualidade da safra de seus associados no ritmo imposto pelo processo produtivo e de modo padronizado, de um jeito que eles saibam prontamente o valor do seu produto.

Essa informação deve ser obtida rapidamente, já que o preço pelo qual essas commodities são negociadas podem ser muito voláteis. A qualidade de uma safra geralmente é avaliada pela análise de pequenas amostras, visando identificar e quantificar os grãos defeituosos e impurezas, os quais podem depreciar sobremaneira o sabor e o aroma da bebida produzida, e consequentemente o seu valor. Grãos defeituosos são aqueles que apresentam alterações físicas e químicas comprometedora, e podem ser provenientes de diversos fatores ocorridos durante o ciclo de vida do café, do cultivo e da colheita, ao beneficiamento e armazenamento. Impurezas são qualquer corpo estranho que não é café encontrado junto dos grãos. A qualidade da amostra é dada de maneira quantitativa ao se computa o número de ocorrências dos diversos tipos de defeitos e impurezas, os quais geralmente têm pesos diferentes na contagem, já que podem depreciar a bebida em proporções distintas. O café pode ser classificado de acordo com os seguintes critérios: por tipo ou defeito, pela característica de qualidade e pela qualidade (Toledo, 1998).

Tendo tais informações em mente, esse trabalho propõe a utilização do algoritmo K-Means para análise de amostras de café em grãos pela análise de imagens digitais, a fim de se aumentar a velocidade e reduzir as subjetividades envolvidas no atual processo manual de classificação. Este artigo está separado em 5 seções, a seção 1 contextualiza o trabalho desenvolvido, a seção 2 apresenta o propósito da classificação do café. A seção 3 descreve o método do algoritmo desenvolvido, na seção 4 os resultados são apresentados, a seção 5 mostra as discussões e 6 a conclusão.

\section{PROPÓSITO}

Atualmente, a avaliação de qualidade é feita visualmente por especialistas e apresenta as seguintes desvantagens: a análise é dependente da interpretação subjetiva do avaliador, de modo que diferentes avaliadores podem dar diferentes diagnósticos para a mesma amostra; é um processo lento, já que cada grão deve ser avaliado individualmente; e a qualidade da análise se deprecia ao decorrer do turno de trabalho, por fatores envolvendo, principalmente, a fadiga. Essas questões fazem dessa análise um processo caro e não totalmente confiável, dadas as subjetividades envolvidas.

\section{MÉTODO}

A metodologia utilizada neste trabalho é dividida em: aquisição de imagens da amostra, aplicação de algoritmos de processamento de imagem para detecção dos objetos e extração de suas características (área, cor e forma) utilizando o software livre Python e, finalmente a classificação utilizando a clusterização por K-Means.

\subsection{Amostragem e Classificação}

Um conjunto de amostras de grãos defeituosos, impurezas e grãos saudáveis de diversos locais, foi obtido através da parceria realizada entre os campi Serra e Alegre do IFES (Instituto Federal de Ciência e Tecnologia do Espírito Santo). Todas as amostras foram previamente separadas e classificadas por especialistas.

As classes de café e suas classificações foram retiradas de acordo com (Revista Cafeicultura, 2007).

Os tipos de grãos que iremos analisar neste trabalho são bom, escuro, marinheiro e brocado.

\subsection{Aquisição de Imagens}

Para capturar a imagem dos grãos de forma sempre metódica, utilizamos um suporte em madeira para fixar uma câmera e os grãos ficam abaixo dispostos e sem se encostar sobre uma folha de papel branco.

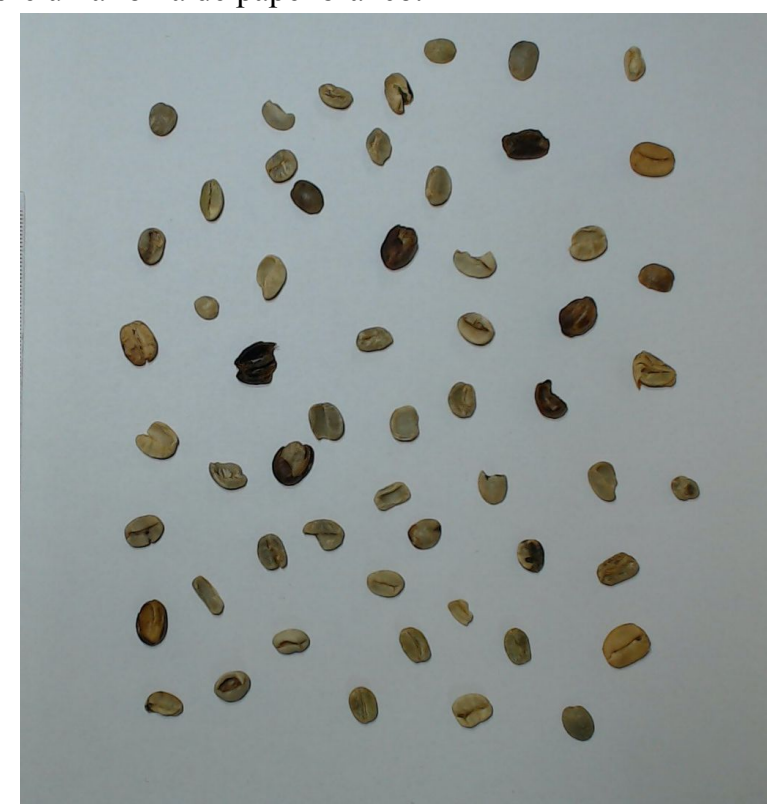

Fig. 1 Grãos espalhados sem processamento.

\subsection{Processamento e White-Patch}

Em Python, foi utilizado a biblioteca OpenCV para realizar o processamento de imagem, por disponibilizar de forma clara várias funções pertinentes ao trabalho.

Foi utilizado também um algoritmo para melhoria e padronização da luminosidade das imagens de amostra, o White-Patch, que é pertencente a família Retinex (E. H. Land, 1997). Rodamos o teste com e sem o algoritmo a fim de verificar se havia melhora na precisão

O White-patch consiste em alterar os valores da matriz de cores, baseado no maior valor original sendo mudado para 255 em RGB e os outros pontos sendo mudados a mesma escala. 


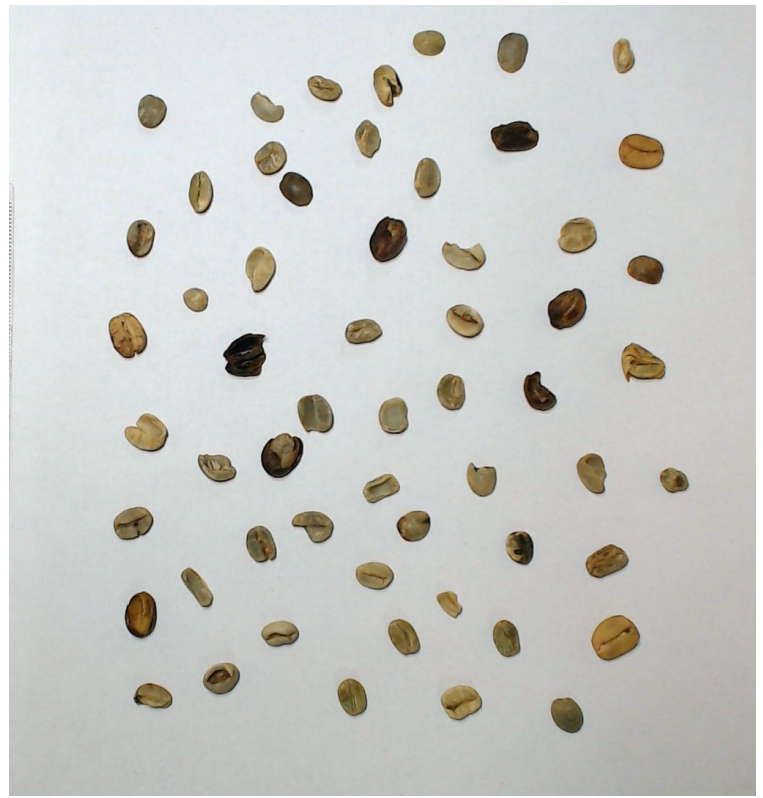

Figura 2. Figura 1 após White-Patch.

A segmentação foi realizada pela binarização de Otsu para desmembrar os grãos da base de fundo, preenchimento de pequenas lacunas presentes deixadas pela binarização e a utilização da função de achar contornos do OpenCV. Ao achar tais contornos, conseguimos separar cada grão de forma ressaltada e numerada.

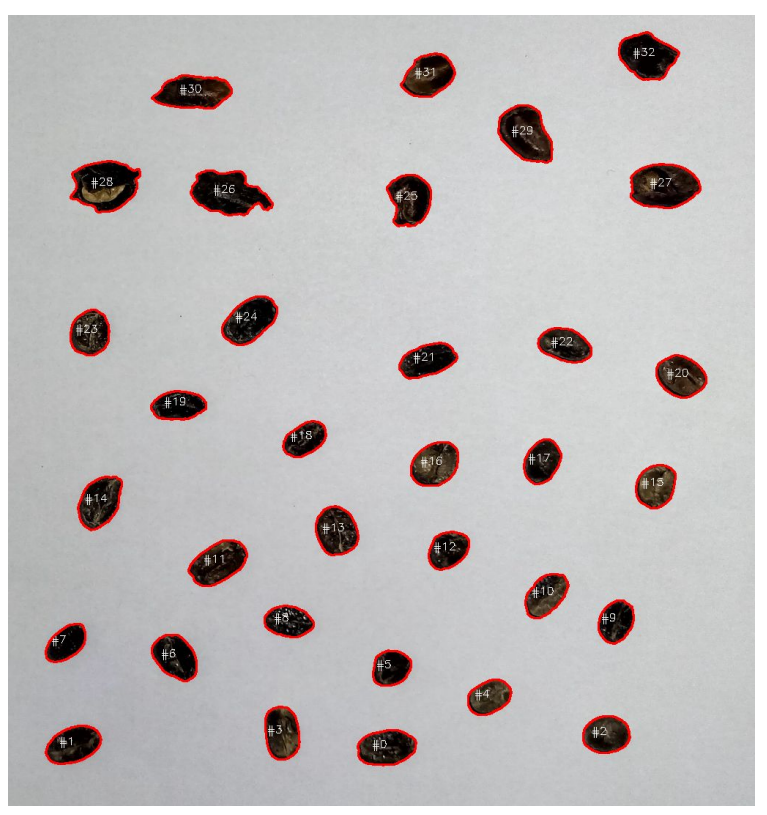

Figura 3. Grãos com contorno marcado e enumerados.

\subsection{Extração de Características}

Para realizar a extração de características, trabalhamos com o grão dentro de seu contorno. Usamos a função da área em OpenCV para obter a quantidade de pixels presentes. Obtemos o arredondamento através da equação:

$$
R=\frac{(4 \cdot \pi \cdot \text { Área })}{\text { Perímetro }^{2}}
$$

O resultado de (1) é um valor entre 0 e 1, quanto mais próximo de 1, mais perto de um círculo perfeito o grãos é.

A extração da cor é feita acessando a matriz RGB, onde cada canal possui valores em cada pixel da imagem, variando de 0 a 255. Ao ter essa informação em mão, é retirado uma média individual dos canais para ser usada no classificador.

\section{$3.5 \mathrm{~K}$-Means}

No processo de análise de dados, K-means é um dos principais métodos de aprendizado não supervisionado, se dá através da criação de diferentes $\mathrm{k}$ grupos de elementos, que já são conhecidos anteriormente. Cada cluster engloba dados que tem características semelhantes, verificado através de uma análise matemática, como a distância Euclidiana.

\section{RESULTADOS}

No início, foram analisados 88 grãos bons, 41 grãos brocados, 14 marinheiros e 19 escuros, totalizando 162 itens, e sem a utilização de nenhum algoritmo para melhoramento da imagem. Os resultados são mostrados na tabela abaixo:

Tabela 1. Relação de acertos sem WP.

\begin{tabular}{|l|l|l|l|l|}
\hline & Bons & Broc. & Marin. & Escuro \\
\hline Bons & 85 & 4 & 0 & 0 \\
\hline Broc. & 0 & 29 & 0 & 0 \\
\hline Marin. & 3 & 8 & 14 & 0 \\
\hline Escuro & 0 & 0 & 0 & 19 \\
\hline $\begin{array}{l}\text { Acerto } \\
(\%)\end{array}$ & $96,59 \%$ & $70,73 \%$ & $100 \%$ & $100 \%$ \\
\hline
\end{tabular}

Mantivemos as mesmas amostras do primeiro teste, porém, desta vez, adicionamos o algoritmo White-Patch para a correção da luminosidade na intenção de se melhorar a precisão do classificador em questão aos brocados, que não haviam dado um resultado muito satisfatório no primeiro teste. $\mathrm{O}$ efeito é visto na tabela 2 :

Tabela 2. Relação de acertos com WP.

\begin{tabular}{|l|l|l|l|l|}
\hline & Bons & Broc. & Marin. & Escuro \\
\hline Bons & 83 & 4 & 0 & 0 \\
\hline Broc. & 5 & 30 & 0 & 0 \\
\hline Marin. & 0 & 7 & 14 & 0 \\
\hline Escuro & 0 & 0 & 0 & 19 \\
\hline
\end{tabular}




\begin{tabular}{|l|l|l|l|l|}
\hline $\begin{array}{l}\text { Acerto } \\
(\%)\end{array}$ & $94,31 \%$ & $73,17 \%$ & $100 \%$ & $100 \%$ \\
\hline
\end{tabular}

\section{DISCUSSÕES}

Ao analisar os dados, a adição de um algoritmo de melhoramento na imagem como o White-Patch não surtiu o efeito que era esperado na classificação, houve um aumento pouco expressivo no número de erros do classificador que tornou sua utilização não desejada e de pouca valia para o projeto.

O número mais elevado de erros dos brocados se deve a dois motivos, sua semelhança com os bons, ao ter brocas de diâmetros muito pequenos, e a média de cada canal de cor, ao ser confundido com marinheiros tendo brocas com maiores diâmetros.

\section{CONCLUSÕES}

Com a chegada da indústria 4.0 e o desenvolvimento de técnicas de processamento de imagem, o uso de visão computacional vem se tornando mais comum em tarefas que antes eram pouco ou nada padronizadas, e executadas de forma manual.

Esse trabalho busca uma forma de substituir o processo atual por um método automático, mais eficiente, confiável e padronizado. A taxa de acerto de 90,74\% (Sem o algoritmo White-Patch) é considerada satisfatória pela literatura, porém, falta explorar mais dos tipos de defeitos dos grãos para se haver uma real implementação. O uso de técnicas mais avançadas, como o deep learning, podem levar a precisões ainda maiores.

Uma possibilidade de trabalho futuro é aprofundar-se nos tipos de grão, apresentando uma gama maior ao adicionar defeitos tais como coco, chocho, quebrado e conchas, de forma a tornar a classificação mais abrangente e eficiente.

\section{AGRADECIMENTOS}

Os autores gostariam de agradecer ao INSTITUTO FEDERAL DO ESPÍRITO SANTO pela bolsa concedida para a realização desta pesquisa e ao Grupo de Automação Industrial (GAIn) pelas instalações usadas no desenvolvimento.

\section{REFERENNCIAS}

E. H. Land et al., The retinex theory of color vision. Citeseer, 1977.

International Coffee Organization (ICO), Exporting Countries: total production, 2014.

Normas de classificação do café. REVISTA
CAFEICULTURA.

$<$ https://revistacafeicultura.com.br/?mat $=13103>$.Acesso em: 03 Set. de 2018.

Toledo, J.L.B., Classificação e degustação de café. Ed. Rio de Janeiro: Sebrae, 1998. 